\title{
Gestão dos resíduos do setor industrial sucroenergético: estudo de caso de uma usina no município de Rio Brilhante, Mato Grosso do Sul
}

\author{
Maria Aparecida Farias de Souza Nogueira', Marli da Silva Garcia² \\ 'Doutaranda em Ciências Ambientais e Sustentabilidade Agropecuária pela Universidade Católica Dom Bosco - Campo Grande, MS - Brasil \\ ${ }^{2}$ Doutoranda em Ciências Ambientais e Sustentabilidade Agropecuária pela UCDB - Campo Grande, MS - Brasil
}

\begin{abstract}
Resumo
O setor sucroenergético tem proporcionado o desenvolvimento socioeconômico nas regiões onde estão implantadas as usinas de açúcar e álcool com geração de empregos diretos e indiretos, que é o fato gerador de renda. É necessário que haja um monitoramento das atividades desenvolvidas dentro do processo produtivo com a implantação de um PGRS (Plano de Gerenciamento de Resíduos Sólidos), para que o desenvolvimento não traga alto custo ao meio ambiente e, consequentemente, à saúde e ao bem estar da população. A pesquisa foi realizada como estudo de caso da gestão dos resíduos em uma usina no Mato Grosso do Sul, por meio de pesquisa exploratória, visitas técnicas e aplicação de questionário. Sobre o manejo dos resíduos e as práticas de sustentabilidade para reduzir os impactos ambientais, a pesquisa revelou alguns pontos importantes: a agroindústria estudada adota a política de reaproveitamento dos resíduos gerados visando o desenvolvimento sustentável de suas atividades.
\end{abstract}

Palavras-Chave: Cana de açúcar, subprodutos, sustentabilidade, resíduos.

\begin{abstract}
The sugarcane industry has provided socio-economic development in the regions where they are deployed sugar mills and alcohol to generate direct and indirect jobs, is the fact that income generator. There must be monitoring of activities within the production process with the implementation of a SWMP (Plan Solid Waste Management), so that development does not bring high cost to the environment and consequently the health and welfare of population. The survey was conducted as a case study of waste management at a plant in Mato Grosso do Sul, through exploratory research, technical visits and questionnaire. On waste management and sustainability practices to reduce environmental impacts, the survey revealed some important points: agribusiness study adopts the policy of reuse of waste generated for the sustainable development of its activities.
\end{abstract}

Keywords: Sugar cane by-products, sustainability, waste. 


\section{INTRODUÇÃO}

O sistema agroindustrial da cana de açúcar é um dos mais tradicionais do Brasil e teve grande influência no período de colonização e na proclamação da república atingiu o terceiro lugar nas exportações brasileiras, atrás apenas do café e da borracha. Atualmente, o Brasil é o maior produtor de cana de açúcar e maior exportador de açúcar.

O Brasil é reconhecido e elogiado mundialmente pelo forte componente renovável de sua matriz energética. Hoje, mais de $47 \%$ de toda a energia utilizada no país vem de fontes renováveis. O setor sucroenergético tem papel-chave nesse quadro: a cana-de-açúcar, matéria-prima para a produção de etanol e bioeletricidade, é a segunda maior fonte de energia do país, respondendo por $18 \%$ de toda a energia consumida pelo Brasil União da Indústria da Cana de Açúcar (UNICA, 2012).

O território brasileiro se destaca mundialmente neste setor devido às vantagens conferidas pelo seu tamanho, pelas condições climáticas e pelas técnicas de plantio desenvolvidas no País. $\mathrm{O}$ setor sucroenergético vive atualmente uma oportunidade histórica, o setor gera etanol, açúcar e energia elétrica de forma sustentável, competindo com o petróleo que é uma fonte de energia esgotável e poluente, o setor sucroenergético atende a necessidade urgente da humanidade de encontrar fontes alternativas e sustentáveis de energia. As mudanças climáticas e a preocupação em reduzir as emissões de carbono na atmosfera têm aberto portas para que a prática de cogeração de energia (entre outras atividades das usinas) seja inserida no mercado de carbono.

Assim o objetivo desta pesquisa foi efetuar um estudo de caso da gestão dos resíduos em uma usina no Mato Grosso do Sul, no município de Rio Brilhante.

\section{CANA DE AÇÚCAR}

A cana de açúcar é originada da Nova Guiné e foi introduzida na América por Cristóvão Colombo e, no Brasil por Martin Afonso de Souza, no ano de 1532 (ZANOTTI, 2007).

Inicialmente a cana foi plantada como planta ornamental, depois sendo utilizada para garapa, açúcar e aguardente. Atualmente a cana de açúcar é matéria prima para muitos produtos como: açúcar, álcool, energia (DINORAH, 2008).

No século XVI, a cana passou a ocupar terras férteis e para facilitar a exportação do açúcar para a Europa, expandiu-se no Nordeste brasileiro, ocupando a Mata Atlântica. A atividade canavieira foi à primeira atividade agroindustrial do Brasil. Em São Paulo, grande centro das indústrias sucroalcooleiras, após alguns períodos onde perdeu importância para a atividade do café, e em Minas para a mineração, a cana reencontra relevância a partir de 1933 com a criação do Instituto do Açúcar e do Álcool por Getúlio Vargas (IAA), que passou a regulamentar o setor, distribuindo cotas entre as usinas para a produção de açúcar, a comercialização com preços fixos e cotas para a exportação (ROSSETO, 2008).

A lavoura de cana de açúcar continua em expansão no Brasil. As áreas em produção continuam com progressivo aumento nos Estados de: Mato Grosso do Sul 12,5\%, Goiás 7,9\%, Espírito Santo 7,35\%, Bahia 5,3\%, Mato Grosso 5,5\%, e Minas Gerais (3,5\%) Companhia Nacional de Abastecimento (CONAB, 2012).

A área cultivada com cana de açúcar que será colhida e destinada à atividade sucroalcooleira na safra 2012/13 está estimada em 8.567,2 mil hectares, distribuídos em todos estados produtores conforme suas características. O estado de São Paulo é o maior produtor com 51,66\% (4.426,45 mil hectares), seguido por Minas Gerais com $8,97 \%$ (768,64 mil hectares), Goiás com 8,54\% (732,02 mil hectares), Paraná com 7,17\% (614,01 mil hectares), Mato Grosso do Sul com 6,31\% (540,97 mil hectares), Alagoas com 5,35\% (458,09 mil hectares) e Pernambuco com 3,48\% (298,39 mil hectares). Nos demais estados produtores as áreas são menores, com representações abaixo de 3\%. A produtividade média brasileira está estimada em $70,289 \mathrm{~kg} / \mathrm{ha}, 2,9 \%$ maior que na safra 2011/12, que foi de $68.289 \mathrm{~kg} /$ há (CONAB, 2012).

A previsão do total de cana moída na safra 2012/13 é de 602,2 milhões de toneladas, com aumento de $5,4 \%$ em relação à safra $2011 / 12$, que foi de 571,4 milhões de toneladas, significando que a quantidade que será moída deve ser 30,7 milhões de toneladas a mais que a moagem da safra anterior. A produção de cana da região Centro- Sul deve ser de 532,0 milhões de toneladas, 6,1\% maior que a produção da safra anterior (CONAB, 2012).

O progresso do setor sucroalcooleiro observado no Brasil foi baseado no uso de apenas um terço do potencial energético da cana-de-açúcar: o caldo, para produção do açúcar e etanol. Agora estamos no limiar do uso em larga escala dos outros dois terços da planta - o bagaço e a palha - para gerar eletricidade, conhecida como bioeletricidade (JANK; RODRIGUES, 2007). 
O presidente da Biosul - Associação de Produtores de Bioenergia de Mato Grosso do Sul, Roberto Hollanda Filho relata que o setor sucroenergético em Mato Grosso do Sul fechou a safra 2012/2013 com a exportação de 1.292 giga Watts hora (GWh) de energia, um crescimento de $17 \%$ em relação a safra passada $(2011 / 2012)$. "Na última safra, nove das 22 usinas injetaram $17 \%$ a mais de bioeletricidade a partir do bagaço da cana no sistema elétrico", apontou o presidente. Percentualmente, o estado foi o primeiro em tonelada de cana moída por exportação de bioeletricidade em todo o País.

Hollanda (2013) enfatiza que a eletricidade a partir da cana é uma alternativa interessante porque complementa a geração hídrica no período de seca, entre abril a novembro, as unidades sucroenergéticas estão moendo para produzir açúcar e etanol e gerando energia a partir da queima do bagaço. $\mathrm{O}$ investimento das usinas em novas plantas e a readequação das antigas, com aquisição de maquinários mais modernos garantiu que esse bagaço fosse transformado em eletricidade. A iniciativa privada também investiu na construção de linhas de transmissão, o que possibilitou que a indústria de cana-de-açúcar tivesse mais um produto: a bioeletricidade.

$\mathrm{Na}$ avaliação de Hollanda (2013) em face ao potencial, a cogeração da bioeletricidade a partir da cana-de-açúcar ainda é tímida. "A indústria tem feito sua parte, agora é necessário estruturar investimentos principalmente as formas de comercialização". Atualmente existem duas formas de comercialização desse produto. Uma delas é a venda direta para os grandes consumidores e a outra é por meio de leilões.

\section{I Resíduos gerados pelo setor sucroenergético}

O setor é conhecido por gerar grande quantidade de resíduos, por sua dimensão. O setor desenvolveu-se dimensionando a retirada dos resíduos da unidade industrial em velocidade praticamente proporcional à sua geração, pois seria impraticável o armazenamento de todos os resíduos nos períodos de produção (JENDIROBA, 2006).

Vilaça (2012) destaca que implantação de um sistema de gestão ambiental em uma usina promove a ordem e consistência na administração dessas questões através da previsão, priorização e distribuição de recursos (humanos, financeiros, materiais), atribuição de responsabilidades e avaliação de suas atividades, sendo um processo contínuo e interativo.

Quando os resíduos sucroenergético não são bem gerenciados, aumentam sobremaneira os riscos de problemas ao meio ambiente, contudo, quando bem utilizados, diminuem significativamente os custos de produção, melhoram a imagem da empresa e as perspectivas de negócios e, principalmente, diminuem os riscos de danos ambientais.

Assim, os interessados beneficiarão de atividades de projetos que resultem em reduções certificadas de emissões. Este processo se dá mediante investimentos em tecnologias mais eficientes, substituição de fontes fósseis por renováveis, e racionalização do uso de energia e reflorestamento, devendo conduzir a resultados mensuráveis e estar exclusivamente relacionados a determinados tipos de gases e setores responsáveis pela maior parte das emissões (GODOY, 2005).

\subsection{A sustentabilidade do setor sucroalcooleiro}

A busca por alternativas de utilização de resíduos industriais tornando-os apenas subprodutos e ainda agregar valor tornou-se uma busca incessante de todas as cadeias produtivas. Buscas por processos de sustentabilidades e aumento dos ganhos faz com que produtos antes considerados problemas passem hoje a ser fontes de renda consideráveis para todas as empresas (CHUBA et al., 2010).

A sustentabilidade é um ideal sistemático que se perfaz principalmente pela ação, e pela constante busca entre desenvolvimento econômico e ao mesmo tempo preservação do ecossistema (ABREU, 2010).

Sustentabilidade é de fato um conceito sistêmico, relacionado com a continuidade de aspectos econômicos, sociais, culturais e ambientais da sociedade humana que, preservam a biodiversidade e os ecossistemas naturais, planejando e agindo em sua manutenção. Estes projetos de sustentabilidade ambiental são um meio de configurar as atividades humanas, de tal forma que a sociedade e as suas economias possam satisfazer as suas necessidades e expressar o seu maior potencial no presente (VILAÇA, 2012).

Para uma melhor visualização e entendimento, segue Fluxograma ilustrando a produção de açúcar, etanol, bioeletricidade e resíduos (Fig.1).

\subsection{Bagaço/palha}

Entre as vantagens que tornam o uso do bagaço uma alternativa competitiva para a cogeração de energia mecânica e elétrica, Pellegrini (2002) cita: a) a lavoura da cana é organizada e os custos de produção do bagaço são debitados no produto nobre, o açúcar e/ou o álcool; b) o 


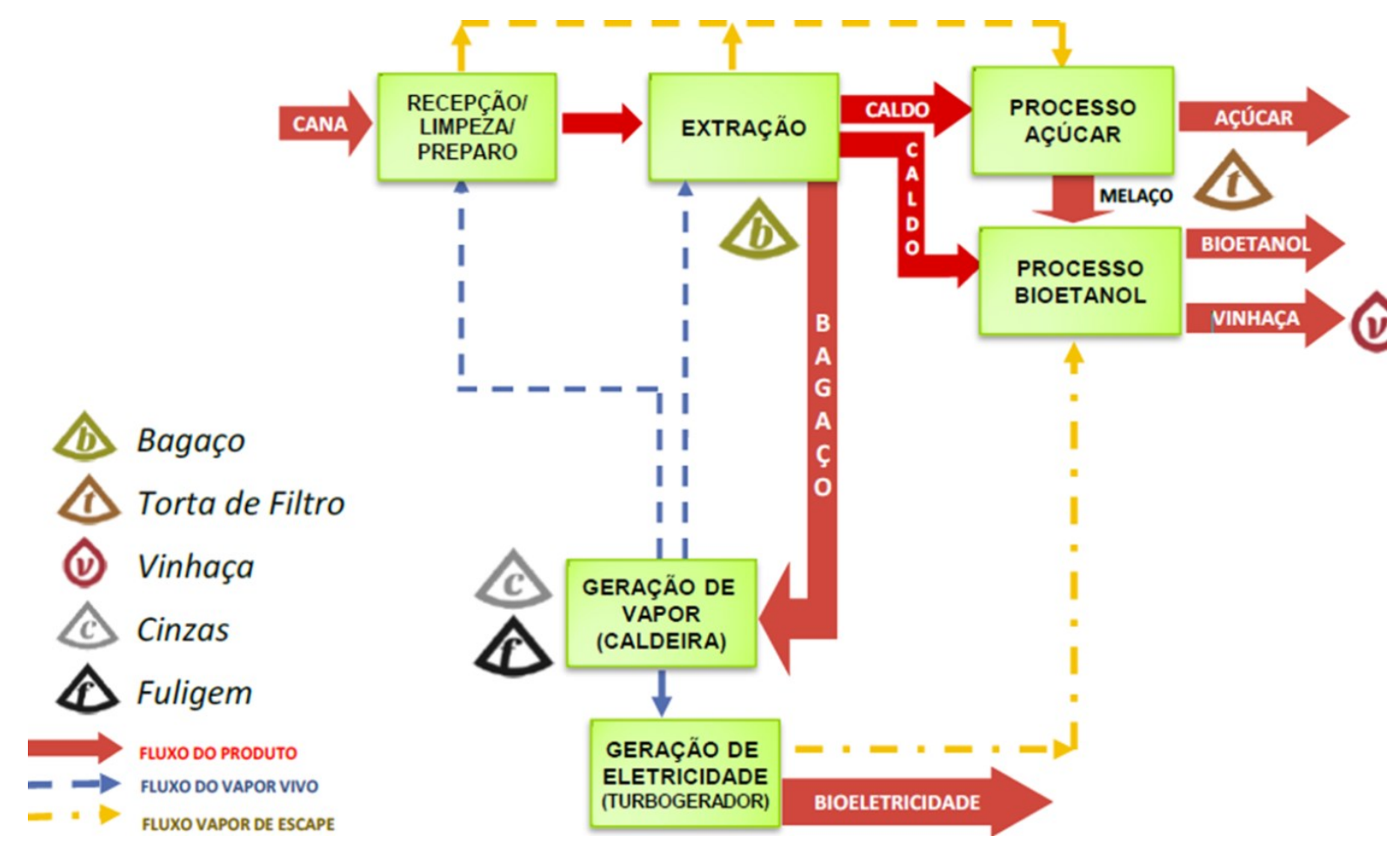

Figura 1: Produção de açúcar, etanol, bioeletricidade e resíduos Fonte: Gurgel, 2012

sistema de transporte entre campo e indústria é organizado e vinculado ao mesmo produto nobre; c) a produção de bagaço é grande e concentrada e o produto é liberado semibeneficiado depois da moagem da cana.

Segundo a União da Indústria de Cana de Açúcar (Unica, 2012), uma tonelada de cana produz em média $280 \mathrm{Kg}$ de bagaço e $234 \mathrm{Kg}$ de palha e pontas. Considerando apenas o bagaço seria possível gerar 85,6 kWh de energia de exportação, utilizando caldeira de 65 bar. Supondo a utilização de $75 \%$ do bagaço disponível em 2012/13 e 50\% da palha disponível no mesmo ano, uma tonelada de cana poderia gerar $210 \mathrm{kWh}$ para exportação. Finalmente, uma tonelada de bagaço gera 342,4 $\mathrm{kWh}$ para exportação enquanto que uma tonelada de palha gera $500 \mathrm{kWh}$ em função da menor umidade.

A bioeletricidade é uma energia limpa e renovável, feita a partir da biomassa: resíduos da cana de açúcar (bagaço e palha), restos de madeira, carvão vegetal, casca de arroz, capim-elefante e outras. No Brasil, $80 \%$ da bioeletricidade vêm dos resíduos da cana-de-açúcar. Com alto teor de fibras, o bagaço de cana, desde a revolução industrial, tem sido empregado na produção de vapor e energia elétrica para a fabricação de açúcar e etanol, garantindo a autossuficiência energética das usinas durante o período da safra. ÚNICA (2012)

Para Moeda (2012) o bagaço com 50\% de

umidade oferece poder calorífico inferior de 7,49 MJ.kg- ${ }^{1}$; a 20\% de umidade esse valor passa a ser de 13,57 MJ.kg- ${ }^{1}$. Um poder calorífico de 18,62 MJ.kg- ${ }^{1}$ pode ser alcançado com a queima do bagaço para geração de eletricidade

De acordo com a definição de Ripoli, T. e Ripoli, M. (2009), palhiço é o material que fica sobre o solo após a colheita mecanizada (antes eliminado pela queima da plantação na fase da pré-colheita), constituído de folhas verdes, palha, ponteiros e suas frações, fracos de colmos (industrializáveis ou não), frações de raízes e partículas de terra a eles aderida.

Segundo Ripoli (2001), podem permanecer no campo de 9 a 28 t. ha de palhiço, dependendo das condições da cultura. A quantidade de palhiço por hectare de é 14,4 t de matéria seca, equivalente a $14 \%$ dos colmos de cana-de-açúcar, segundo o Centro de Tecnologia Canavieira (CTC) da Coopersucar (2005). Para os 350 milhões de toneladas de cana-de-açúcar produzidos nacionalmente há um potencial de coleta de 49 milhões de toneladas de palhiço matéria seca.

Sartori (2001) defendeu que a disponibilidade de palhiço muda de acordo com a variedade de cana e os diferentes números de corte Segundo Furlani Neto et al. (1997), após a colheita mecânica em canaviais sem queima prévia, a quantidade de palhiço encontrada é de 24,32 t.ha-1 para SP 71- 1406 e 10,25 t.ha-1 para SP71-6163; contra 
13,51 t.ha-1 e 8,09 t.ha-1, respectivamente, após a colheita mecânica com cana queimada.

\subsubsection{Torta de Filtro}

É resultante do processo do filtro a vácuo ou do filtro prensa do lodo recebido do decantador de caldo, a quantidade gerada deste produto é em média $40 \mathrm{~kg} /$ tonelada de cana e sua disposição final é a lavoura e/ou compostagem.

As impurezas presentes no caldo de cana são removidas através de floculação ou decantação, resultando um lodo rico em açúcar, que é tratado em filtro rotativo a vácuo, que extrai o açúcar residual através de lavagem e filtração. Resulta desta operação a torta de filtro, um resíduo sólido produzido na proporção de $1 \%$ a $4 \%$ do peso da cana moída. Este resíduo é, então, prensado para reduzir sua umidade, que inicialmente é de $75 \%$. A torta de filtro é produzida de forma contínua, sendo que cada tonelada de cana produz $40 \mathrm{~kg}$ de torta (CTC, 2008).

É constituída de cerca de 1,2 a $1,8 \%$ de fósforo e cerca de $70 \%$ de umidade, que é importante para garantir a brotação da cana em plantios feitos em épocas de inverno nas Região Sul e Sudeste. A torta também apresenta alto teor de cálcio e consideráveis quantidades de micronutrientes. Sua aplicação é feita em área total ou diretamente no sulco de plantio. (ROSSETO; SANTIAGO, 2007).

\subsubsection{Vinhaça}

Conhecido como vinhaça, vinhoto ou restilo, é o líquido derivado da destilação do vinho, que é resultante da fermentação do caldo da cana de açúcar ou melaço. O volume varia basicamente entre 10 a 15 litro/litro de álcool, dependendo do teor alcoólico do vinho e o vapor direto utilizado.

A vinhaça é um resíduo ácido $(\mathrm{pH} \mathrm{4,0} \mathrm{a}$ 4,8 ), de cor escura, com alta demanda bioquímica de oxigênio - DBO médio de 19.800 mg L-1 (caldo + mel) (Glória, 1983), e emite um cheiro forte característico. Aproximadamente de 10 a 18 litros de vinhaça são obtidos por 1 litro de etanol produzido e sua composição varia de acordo com a matéria prima e equipamentos utilizados no processo de obtenção do etanol (WADT, 2008).

Dos efluentes produzidos pelas destilarias de etanol, a vinhaça é a que possui a maior carga poluidora. A vinhaça constitui um dos grandes problemas ambientais, quando lançada nos meios hídricos, em função da alta demanda bioquímica de oxigênio (DBO) possuindo ação redutora extremamente alta e requerendo elevada taxa de oxigênio para estabilizar-se. Resiste tenazmente aos métodos usuais de tratamentos de resíduos, é muito volumosa, apresentam características ácidas e corrosivas, o que dificulta o seu armazenamento e transporte sem prévio tratamento (SZMRECSÁNYI et al, 2008).

A vinhaça é empregada no setor agrícola como fertilizante principalmente nos cultivos de cana de açúcar. Este resíduo pode promover melhoria na fertilidade do solo, no entanto, as quantidades não devem ultrapassar sua capacidade de retenção de íons, ou seja, as dosagens dependem das características do solo. A quantidade a ser utilizada deve considerar a profundidade e a fertilidade do solo, a concentração de $\mathrm{K}$ na vinhaça e a extração média desse elemento pela cultura, conforme fórmula constante no item 6 da Norma Técnica CETESB-P4.231(GURGEL, 2012).

Os seguintes efeitos benéficos da aplicação da vinhaça no solo podem ser enumerados: (i) elevação do $\mathrm{pH}$; (ii) aumento da disponibilidade de alguns íons; (iii) aumento da capacidade de troca catiônica (CTC); (iv) aumento da capacidade de retenção de água e; (v) melhoria da estrutura física do solo (GLÓRIA; ORLANDO FILHO, 1983).

A vinhaça deve ser vista, também, como agente do aumento da população e atividade microbiana no solo. $\mathrm{O}$ pH dos solos tratados com vinhaça aumenta principalmente em áreas cultivadas há mais tempo (Silva e Ribeiro, 1998), embora nos primeiros dez dias após sua aplicação, o pH sofra uma redução considerável para, posteriormente, elevar-se abruptamente, podendo alcançar valores superiores a sete; este efeito está ligado à ação dos microrganismos (ROSSETTO, 1987).

\subsubsection{Cinzas/Fuligens}

Segundo Gurgel (2012), a cinza é oriunda da queima do bagaço nas caldeiras, são dispostas em áreas de aterro ou aplicadas no solo, são gerados em média $2,06 \mathrm{~kg} /$ tonelada de cana. A fuligem é proveniente do sistema de lavagem de gases instalado na chaminé, é direcionada para lagoas de decantação e sua produção média é de $11,76 \mathrm{~kg} /$ tonelada de cana, seu destino final é a aplicação no solo.

\subsubsection{Outros resíduos}

O lixo comum é um resíduo sólido resultante das atividades de escritório, sanitários e varrição, compostos principalmente de papéis, papelões, plásticos, estopa, são coletados e classificados dando destinados corretos, o lixo que pode ser reciclado destinado à reciclagem, o que não recicla são dispostos no aterro sanitário do Município. 
Têm-se como sucatas ferrosas e não ferrosas os resíduos resultantes da manutenção da indústria, troca de equipamentos, tubos e chaparias. As sucatas ferrosas, principalmente aço carbono e aço inox, são dispostas a granel em local aberto. Já as sucatas não ferrosas, principalmente o cobre e o bronze, são armazenadas em tambores em local próprio. Este material é comercializado no decorrer da safra.

Os óleos lubrificantes usados são considerados como classe I (perigosos), de acordo com a classificação da associação brasileira de normas técnicas (ABNT), e coletadas normalmente em tambores de 200 litros, sendo parte reutilizada na lubrificação de correntes e rodetes das correias transportadoras da usina. A parte restante é armazenada e vendida para empresas recuperadoras de óleo (GURGEL 2012)

\section{METODOLOGIA}

A pesquisa é exploratória, com revisão de literatura nacional e internacional. Para a coleta de dados, utilizou-se a visita técnica, entrevista e questionário com questões abertas e fechadas. Quanto aos meios de investigação, a pesquisa caracterizou-se como um estudo de caso, desenvolvido em uma agroindústria de transformação de cana de açúcar, situada no Estado de Mato Grosso do Sul, no município de Rio Brilhante cujo nome real foi preservado.

De acordo com Beuren (2010) uma característica da pesquisa exploratória consiste no aprofundamento de conceitos preliminares sobre determinada temática não contemplada de forma satisfatória anteriormente. Seguindo o mesmo raciocínio, Marion et al (2009) afirmam que a pesquisa exploratória antecede uma fase de trabalho de campo, pois a considera como pesquisa desenvolvida quando o autor tem pouco conhecimento a respeito do assunto pesquisado. A produção específica é bem variável sendo apresentados números básicos que dão uma ordem de grandeza, baseados em sua maioria nas médias encontradas nas usinas, que devem ser utilizados com critérios, pois variam caso a caso (porte da usina, características do processo e da matéria prima).

Para obtenção dos dados primários foi realizada visita na usina para obter informações técnicas que permitissem melhor compreender os processos e particularidades dos resíduos gerados, assim como os subsistemas adotados para alcançar a sustentabilidade.
A pesquisa busca quantificar os resíduos e coprodutos em uma usina sucroalcooleira do município de Rio Brilhante no Mato Grosso do Sul em função de sua capacidade instalada.

Mato Grosso do Sul conta hoje com 24 usinas instaladas (Biosul, 2013).

A pesquisa foi efetuada analisando-se os dados do período de processamento de produção de julho a agosto de 2013 da usina em questão.

\section{ANÁLISE E DISCUSSÃO DOS RESULTA- DOS}

O município de Rio Brilhante onde está localizada a usina pesquisada tem uma população 31.280, IDH 0,747 médio, PIB de R $\$ 600.120$ mil, é formado de migrantes, que se juntaram aos mato-grossenses, dando uma miscigenação de raças e culturas. Para a cidade vieram os paulistas, nordestinos e sulistas formando uma cultura ímpar. A localização é de fácil escoamento da produção com estradas vicinais de boa qualidade, sendo servida por duas rodovias federais: BR 163 e BR 267, que liga a cidade aos grandes centros ou aos portos, como é o caso do Porto Murtinho no Rio Paraguai. Com isso a cidade está num ponto estratégico, para o Mercosul, estando na rota dos países signatários do Conesul.

A agroindústria estudada processa diariamente em média 10.545 toneladas de cana de açúcar. Produz diariamente:

Açúcar - 18.000 sacas de 50 quilos de açúcar.

\author{
Álcool - 486,57 m \\ Energia elétrica - $38 \mathrm{MWh}$
}

Os resíduos gerando como o bagaço, vinhaça, torta de filtro, cinzas e fuligens são transformados em coproduto e totalmente utilizados dentro dos processos agroindustriais da usina.

\section{I Bagaço}

O bagaço é o resíduo da moagem da cana e sua geração varia conforme as características da matéria-prima. O resíduo bagaço e palha são usados para cogerar energia, através da sua queima nas caldeiras. Segundo Cordeiro et al (2010) os avanços tecnológicos e a necessidade de ampliação do parque de geração de energia elétrica do setor sucroalcooleiro, valorizaram o bagaço como fonte primária de energia que, além de atender a demanda energética das usinas também gera um 
excedente passível de ser comercializado.

A usina estudada tem uma estimativa da geração de bagaço de 230 a $260 \mathrm{~kg}$ por tonelada de cana processada, ou seja, corresponde de $23 \%$ a $26 \%$ da matéria-prima de entrada, sendo que $100 \%$ são queimados na caldeira, cogeração de energia mecânica para alimentar a indústria e o excedente transformado em energia elétrica por uma central de transformação e exportado para o Sistema Integrado Nacional de energia elétrica. A comercialização da energia esta sendo uma das maiores fontes de retorno econômico para a usina. $O$ bagaço é transportado até as caldeiras por meio de esteiras rolantes e o seu excesso é armazenado no pátio da indústria a céu aberto.

\subsection{Cinza}

A cinza é misturada com o resíduo na lagoa, portanto, esse material também é retirado por pá carregadeira e colocado em caminhões basculantes que transportam esse material até a lavoura onde é armazenado a céu aberto para ser utilizado como fertilizante.

A usina estudada indica que são gerados $25 \mathrm{~kg}$ de cinza por tonelada de cana, ou seja, corresponde a 2,5\% da matéria-prima de entrada, que são aproveitadas no campo como fertilizantes.

\subsection{Torta de filtro}

A torta de filtro é o resíduo gerado no processo de filtração do lodo, proveniente do decantador de caldo, que é realizado por um filtro rotativo a vácuo e um filtro prensa. O resíduo é armazenado e transportado por caminhão basculante até a lavoura e estocado a céu aberto para ser utilizado como fertilizante, pois contém matéria orgânica, nitrogênio, fósforo e potássio.

$\mathrm{Na}$ usina estudada a torta de filtro é mis- turada com a cinza na percentagem de 70 e $30 \%$ respectivamente para ser aplicado na fertilização da lavoura. A indústria também estima uma geração de $24,8 \mathrm{~kg}$ de torta de filtro por tonelada de cana que corresponde a $2,48 \%$ da matéria-prima de entrada.

\subsection{Vinhaça}

Vinhaça este efluente é gerada na fase de destilação, é armazenado em lagoas, transportados por dutos até a lavoura próxima da usina, onde é realizada a fertirrigação. Segundo Alvarenga e Queiroz (2009) a vinhaça é um subproduto da indústria sucroalcooleira rica em matéria orgânica, potássio, cálcio e enxofre é utilizada na fertirrigação, pois apresenta vantagens como o favorecimento do desenvolvimento de microrganismos, entretanto, por ser gerada em altas quantidades, pode ser lançada no solo em uma super dosagem para que haja sua eliminação, esse uso inadequado causa impacto tanto no solo quanto no lençol freático. $\mathrm{Na}$ usina pesquisada e estimada uma taxa de geração de vinhaça de 10 a 15 litros por litro de álcool.

\subsection{Palha}

A agroindústria utiliza colheita 100\% mecanizada, não usa nem um tipo de pré-limpeza da cana. Segundo Braunbeck e Oliveira (2006), em função do aproveitamento da palha para aplicações na geração de energia e cobertura vegetal para agricultura convencional ou orgânica, o processo de colheita da cana vem sofrendo mudanças visando o seu aproveitamento integral.

A indústria estudada ainda não utiliza a coleta de palha do campo para cogeração de energia.

Segue a tabela 1 com os resultados finais da produção de resíduos do processo agroindustrial.

Tabela 1 - gestão dos resíduos

\begin{tabular}{|c|c|c|c|c|c|c|c|}
\hline Resíduos & $\begin{array}{l}\text { Local de } \\
\text { geração }\end{array}$ & Quantidade & Classe & $\begin{array}{l}\text { Armazena- } \\
\text { mento }\end{array}$ & Tratamento & Transporte & $\begin{array}{l}\text { Disposição } \\
\text { final }\end{array}$ \\
\hline Bagaço & Moagem & $\begin{array}{l}230 \text { a } 260 \\
\mathrm{Kg} / \mathrm{t} \text {. cana. } \\
23 \% \text { a } 26 \%\end{array}$ & II A & $\begin{array}{c}\text { Pátio, } \\
\text { industrial a } \\
\text { céu aberto. }\end{array}$ & ---------------- & $\begin{array}{l}\text { Caminhão } \\
\text { basculante }\end{array}$ & Caldeira \\
\hline Cinzas & Caldeiras & $\begin{array}{c}25 \mathrm{Kg} / \mathrm{t} \text { cana } \\
(2,5 \%)\end{array}$ & II B & Lagoa & Decantação & $\begin{array}{l}\text { Caminhão } \\
\text { basculante }\end{array}$ & Lavoura \\
\hline Torta de filtro & Filtro & $\begin{array}{c}35 \mathrm{Kg} / \mathrm{t} \text { cana } \\
\quad(3,5 \%)\end{array}$ & II A & $\begin{array}{l}\text { Caminhão } \\
\text { basculante }\end{array}$ & - & $\begin{array}{l}\text { Caminhão } \\
\text { basculante }\end{array}$ & Lavoura \\
\hline Vinhaça & Destilação & $\begin{array}{l}10 \text { a } 14 \text { litros/ } \\
\text { litros de álcool }\end{array}$ & I A & Lagoa & - & Dutos & Lavoura \\
\hline
\end{tabular}




\section{CONSIDERAÇÕES FINAIS}

Baseado no diagnóstico realizado podese afirmar que a indústria canavieira estudada utiliza práticas de manejo sustentável buscando dar destinação aos seus resíduos. Sobre o manejo dos resíduos e as práticas de sustentabilidade para reduzir os impactos ambientais, a pesquisa revelou alguns pontos importantes: a agroindústria estudada adota a política de reaproveitamento dos resíduos gerados visando o desenvolvimento sustentável de suas atividades; possui certificação de responsabilidade ambiental, onde a empresa adota as práticas para preservação do meio ambiente conferindo maior credibilidade para os futuros consumidores de seus produtos tendo em vista que atualmente há uma maior conscientização do mercado consumidor referente às questões ambientais e por isso a cobrança por evidentes resultados. A usina tem profissional especializado na área ambiental para monitorar as práticas sustentáveis dentro de um plano de ação na gestão ambiental, tornando-se uma empresa reconhecida e defensora das questões ambientais.

\section{REFERÊNCIAS}

ABREU, C. Sustentabilidade Ambiental: o que é a sustentabilidade ambiental. 2010. Disponível em: $<$ http://www.atitudessustentaveis.com.br/sustentabilidade/sustentabilidade-ambiental-o-que-e-a-sustentabilidadeambiental/>.Acesso em 07 jun. 2013.

ALVARENGA, R. P. e QUEIROZ, T. R. Produção mais limpa e aspectos ambientais na indústria sucroalcooleira. In: International workshop advances in cleaner production, v 2, 2009, São Paulo.

BEUREN, I. M. Metodologia da pesquisa aplicada às Ciências Sociais. In BEUREN, I. M. Como elaborar trabalhos Monográficos em Contabilidade: Teoria e Prática. 3 ed. São Paulo: Atlas, 2010.

BIOSUL - Associação dos Produtores de Bioenergia de Mato Grosso do Sul. O setor sucroenergético em Mato Grosso do Sul. Disponível em: http://www. novacana.com $/ \mathrm{n} /$ cogeracao/mercado/ms-usinas-exportaram-bioeletricidade-safra- $060313 /$ acesso $06 \mathrm{de}$ Jun. de 2013.

Associadas. Acesso em jul. 2013. Disponível em: < http://www.biosulms.com.br/associados.php>.
CENTRO DE TECNOLOGIA COPERSUCAR. Biomass power generation: sugarcane bagasse and trash. Disponível em: <http://www.ctcanavieira. com.br>, Acesso em: 15 de maio. 2013.

CHUBA, C. A. M.; ARGANDONA, E. J. S.; HOMEM, G. R.; TOMMASELLI, M. A. G. Modelo de Viabilização da Produção do Consórcio: Macaúba (Acrocomia Aculeata) e Cana-De-Açúcar (Saccharum Officinarum). In: XXX Encontro Nacional de Engenharia de Produção. ENEGEP, São Carlos, 2010.

CONAB. Acompanhamento da safra Brasileira. Brasília: Companhia Nacional de Abastecimento, 2012. Apresenta informações sobre a safra da cana-de-açúcar 2012/2013. Disponível em: <http:// www.conab.gov.br/OlalaCMS/uploads/arquivos/12_04_10_09_19_04_boletim_de_cana.pdf $>$. Acesso em: 25 Nov. 2012.

CORDEIRO, G. C.; TOLEDO FILHO, R. D. e FAIRBAIRN, E. M. R. Ultrafine sugar cana bagasse ash: high potential pozzolanic material for tropical countries. Revista IBRACON de estruturas e materiais, v. 3 , n. 1, p. 50-67, mar. 2010.

DINORAH, E. Novas técnicas transformam palha da cana em bioóleo, carvão siderúrgico, carbeto de silício e, no futuro, etanol. Pesquisa FAPESP, São Paulo, n. 154, p. 95-98, dez. 2008.

GLÓRIA, N.A.; ORLANDO F., J. Aplicação de vinhaça como fertilizante. São Paulo: Copersucar, 1983.

GODOY, S. G. M. O Protocolo de Kyoto e o mecanismo de desenvolvimento limpo: uma avaliação de suas possibilidades e limites. 2005. $164 \mathrm{f}$. Dissertação (Mestrado em Economia Política) - Pontifícia Universidade Católica de São Paulo - PUC, São Paulo, 2005.

GURGEL, M. N. A. Tecnologia para aproveitamento de resíduos da agroindústria sucroalcooleira como biofertilizante organomineral granulado. Tese de Doutorado (Universidade Estadual de Campinas / Faculdade de Engenharia Agrícola). Campinas: SP, 2012.

HOLLANDA, R. Presidente da Associação dos Produtores de Bioenergia de Mato Grosso do Sul. Conquistas do setor sucroenergético na matriz energética brasileira, MS. Disponível em <http:// www.novacana.com $/ \mathrm{n} /$ cogeracao/mercado/ms-u- 
sinas-exportaram-bioeletricidade-safra-060313/> Acesso 06 de Jun. 2013.

JANK, M.S.; RODRIGUES, L. Dinâmica e agenda do setor sucroalcooleiro na próxima década. Revista de Política Agrícola (Brazil). (Oct-Nov-Dec 2007), v. 16(4) p. 86-96. ISSN 1413-4969 disponível em: http://www.embrapa.br/publicacoes/tecnico/revistaAgricola/rpa-de-2007/RPA\%204-2007ultima.pdf. Acesso 09 de Abr. 2013.

JENDIROBA, E. Questões ambientais no manejo da agroindústria canavieira. In: SEGATO, S.V.; PINTO, A.S.; JENDIROBA, E.; NÓBREGA, J.C.M. Atualização em produção de cana de açúcar. Piracicaba: CP 2, 2006.

MAEDA, F. Influências do protocolo agroambiental do setor Sucroalcooleiro na produção de açúcar, álcool e Energia: estudo de caso em uma usina no interior do Estado de São Paulo. Dissertação apresentada à Faculdade de Ciências Agronômicas da Unesp - Campus de Botucatu, São Paulo 2012.

MARION. J.C.; DIAS, R.; TRALDI, M.C. Monografia para os cursos de Administração, Contabilidade e Economia. Atlas: São Paulo, 2009.

PELLEGRINI, M. C. Inserção de centrais co-geradoras a bagaço de cana no parque energético do Estado de São Paulo: exemplos de aplicações de metodologia para análise dos aspectos locacionais e de integração energética. 2002. 168 f. Dissertação (Mestrado em Energia)-Universidade de São Paulo, São Paulo, 2002.

RIPOLI, T. C. C. Alternativa energética. Cultivar máquinas, Pelotas, v. 1, n. 4, p. 26-27, 2001.

RIPOLI, T. C. C.; RIPOLI, M. L. C. Biomassa de cana-de-açúcar: colheita, energia e ambiente. Piracicaba: Edição dos Autores, 2009.

ROSSETTO, R.; SANTIAGO, A. D. Adubação: resíduos alternativos. Brasília, DF: EMBRAPA, 2007. Disponível em:<http://www.agencia.cnptia. embrapa.br/gestor/canade-

açúcar/arvore/CONTAG01_39_711200516717. html> Acesso em: 30 Mai. 2013.

ROSSETO, R. A Cana de açúcar e a questão ambiental. In: MIRANDA, L. L. D. ; VASCONVELOS, A. C. M.; LANDELL, M. D. A. Cana de açúcar. Campinas: Instituto Agronômico, 2008.
ROSSETTO, A.J. Utilização agronômica dos subprodutos e resíduos da indústria açucareira e alcooleira. In: PARANHOS, S.B. (Ed.). Cana de açúcar: cultivo e utilização. Campinas: Fundação Cargill, 1987.

SARTORI, M. M. P. Otimização da produção de energia e biomassa do resíduo de colheita em variedades de cana-de-açúcar. 2001. 108 f. Tese (Doutorado em Agronomia/Energia na Agricultura)-Faculdade de Ciências Agronômicas, Universidade Estadual Paulista, Botucatu, 2001.

SILVA, A.J.N.; RIBEIRO, M.R. Caracterização de um Latossolo Amarelo sob cultivo contínuo de cana de açúcar no Estado de Alagoas: propriedades químicas. Revista Brasileira de Ciência do Solo, 1998.

SZMRECSÁNYI, T.; RAMOS, P.; RAMOS FILHO, L.O; VEIGA FILHO, A.A. Dimensões, riscos e desafios da atual expansão canavieira. Texto para Discussão 32. Brasília: Embrapa Informação Tecnológica, 2008.

UNICA - União da Indústria de Cana de açúcar. Conquistas do setor sucroenergético na matriz energética brasileira. Disponível em: http://www. unica.com.br/faq/, acesso em 10 Jun. de 2013.

VILAÇA, A.C.; PINTO, D. C. A. Sustentabilidade do setor sucroalcooleiro. Disponível em: < http://www.fazu.br/ojs/index.php/posfazu/article/ viewFile/467/359> acesso em 24 de jun. de 2013.

WADT, L.C. Cultivo de Pleurotus ssp em vinhaça visando a produção de biomassa e exopolissacarídeos. 2008, Dissertação (Mestrado em Biologia na Agricultura e Ambiente), Universidade de São Paulo). Centro de Energia Nuclear na Agricultura, Piracicaba, 2008.

ZANOTTI, N. E. (Coord.) Plano estratégico de desenvolvimento da agricultura capixaba: estudo setorial cana-de-açúcar. Vitória, ES: SEAG-ES, 2007. 46 p. Disponível em: <www.seag.es.gov.br/ pedeag/setores/cana.pdf>. Acesso em: 01 jun. 2013. 